\title{
South Africa boosts funding for universities
}

Cape Town. The South African government has announced that it plans to increase spending on universities and 'technikons' higher technical institutes - by more than 23 per cent next year. This represents an increase of R830 million (US\$231 million) in its support for higher education.

The move follows the determination of the coalition government led by the African National Congress, and expressed through the efforts of the Minister of Education, Sibusiso Bengu, to stop the downward slide in subsidies that has taken place over the past decade. Bengu, a former rector of the University of Fort Hare, is acutely aware of the problems that this has posed for the universities.

But the increase will not be uniform. Universities will receive 20.9 per cent more than last year, while technikons will receive an additional 31 per cent. This reflects the fact that the funding system has in the past been skewed in favour of universities, as well as the government's determination to encourage the acquisition of technical skills among school-leavers.

As the full budget will be announced only in March, it is not yet clear where the government is cutting back to make more funds available for tertiary education. In the past, tertiary education has received 15 per cent of the education budget, and the increases may either reflect an overall increase in the education budget, or may be at the expense of state expenditure on schools.

As previously, grants to individual institutions will be made according to the so-called 'SAPSE' formula. This is based primarily on levels of student enrolment and success with different weighting for science and arts courses and undergraduates as opposed to postgraduates — but also incorporates research output.

To decide the actual subsidy received, the score registered by an individual institution is multiplied by a so-called 'A factor', which represents the proportion of its entitlement that the state can afford to finance. This has been increased from 62.8 to 66.2 per cent for universities, and 61.1 to 68.2 per cent for technikons.

Both types of institutions are expected to make up the balance in operating costs from student fees. But the cumulative effect of rising fees over the past decade has led to serious payment problems, particularly at universities with large numbers of black students. Earlier this month, for example, the University of the Western Cape (UWC) was forced to close temporarily following disruptions that had resulted from the university's refusal to register students who had

\section{Funding agency names new president}

Cape Town. The South African Foundation for Research Development (FRD) announced last week that Khotso Mokhele, one of its two vice-presidents, will become its new president from 1 April. Mokhele, who will take over the post on the retirement of Rein Arndt, will be the first black person to head a science council in South Africa.

Mokhole becomes head of the government's principal funding agency for science and engineering research at a time of growing concern about research funding in South Africa. "The FRD is R30 million (US\$ 8 million) short of what it requires to implement its research programmes this year," he says. "A critical task will be to mobilize these funds."

$\mathrm{He}$ admits that an even more important challenge will be to change the demography of the science and technology community in South Africa, in terms of both race and sex; 30 per cent of scientists working in South Africa are women, but only 15 per cent are not white. In engineering all but five per cent are white, with only 1.6 per cent of engineers being female. "But at the same time we shall have to ensure that the quality of both our research and our

graduate students is not only maintained but enhanced."

Born in Bloemfontein, Mokhele, who is 40 , is a microbiologist who studied as

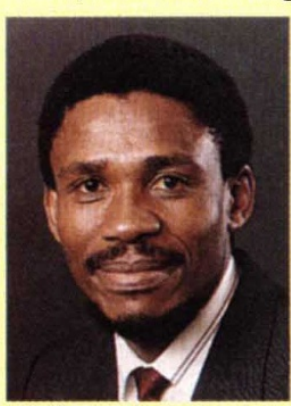

Mokhele: first black to head science council.

can Society of Microbiolog Ingraham.

After spending a year as a postdoctoral fellow in the laboratory of the Nobel prizewinner Hamilton Smith at Johns Hopkins University in Baltimore, Maryland, Mokhele returned to a faculty position at the University of Fort Hare for three years. He then moved to the University of Cape Town in 1990, before being appointed to his current position at the FRD in 1992. not paid last year's fees.

The increased subsidy will affect institutions in different ways, primarily reflecting different levels of increase in enrolment in 1994 (subsidies are calculated on the basis of figures two years before their payment). UWC will benefit the most, with an increase in its subsidy of 49.39 percent.

In contrast, the University of the Witwatersrand will receive an increase of only 8.8 per cent, while two of the former 'homeland' universities of Transkei and Bophuthatswana will suffer cuts of between 6 and 7 per cent. This is because their 'A factors', which were significantly higher than the other universities over the past few years as a consequence of receiving special treatment from the previous government, have now been brought more into line.

In addition to the 'A factor' increase, the part of the formula corresponding to academic and administrative staff salaries has also been increased. Hugh Amoore, registrar of the University of Cape Town, says that the government's recognition that academic salaries are lagging is important, but that the funding of either bursaries or loans for indigent students has still not been adequately addressed.

The increases have been welcomed by Andre de Wet, registrar of finance at UWC. "Now we can look at putting some more staff in the lecture halls as well as improving our laboratories and libraries," he said.

As individual institutions have the autonomy to manage their own finances, universities may also choose to respond to the increases by limiting fee rises next year, by directing more funds into their own loan or bursary schemes, and by raising salaries by different amounts.

The National Commission on Higher Education, appointed more than a year ago under the chairmanship of Jayairam Reddy, former rector of the University of DurbanWestville, is due to present its final report to government by the end of July. Its brief is to completely revamp the funding system for tertiary education. This follows widespread criticism that the SAPSE formula does not relate to South Africa's graduate needs, as it does not dictate the number of places that the state subsidizes in each discipline.

Despite weightings in favour of students registered in the natural sciences in terms of the formula, this has led to a situation in which the proportion of university graduates in science and engineering fell from 17 to 13 per cent of the total, and those in medicine from 11 to only seven per cent, between 1982 and 1992. An additional possibility being considered by the commission is the amalgamation of the universities and technikons into a single sector, as has recently taken place in the United Kingdom.

Michael Cherry 